\title{
Gestational Effects of Corticosteroids and Surfactant in Ventilated Rabbits
}

\author{
MACHIKO IKEGAMI, ALAN H. JOBE, STEVEN SEIDNER, AND TAKAKO YAMADA
}

Department of Pediatrics, Building A-17 Annex, Harbor-UCLA Medical Center, UCLA School of Medicine, 1000

West Carson Street, Torrance, California 90509

\begin{abstract}
Maternal corticosteroid treatments decreased lung protein leaks and increased the compliance responses to exogenous surfactant in 27-day preterm rabbits. We asked if maternal corticosteroid treatments at different gestational ages might alter these responses Pregnant does were given $0.1 \mathrm{mg} / \mathrm{kg}$ betamethasone 48 and $24 \mathrm{~h}$ before study of the rabbits at 27,28 , and 29 days of gestational age and term newborns at 31 days of gestational age. Alternate rabbits at each gestation were treated with $50 \mathrm{mg} / \mathrm{kg}$ surfactant after delivery. Alveolar saturated phosphatidylcholine pool sizes increased with gestation similarly in control and corticosteroid-treated groups. Corticosteroids improved compliance relative to control values at 29 days of gestational age in animals not treated with surfactant and improved the compliance response to surfactant treatment at $\mathbf{2 7}$ and 28 days of gestational age. Corticosteroids decreased the leak of radiolabeled albumin to the lungs and alveolar washes at all preterm gestations with a maximum decrease to $16 \%$ of the control value at 29 days of gestation. Surfactant decreased this protein leak more effectively than did corticosteroids at the earlier gestations. There were potentially beneficial effects of corticosteroids either alone or together with surfactant at all preterm gestations studied. No protein leak or compliance effects of either treatment were noted in the term newborns. (Pediatr Res 25:32-37, 1989)
\end{abstract}

Maternal corticosteroid treatments are used routinely to decrease the incidence of respiratory distress syndrome in preterm infants (1). Recent clinical trials indicate that surfactant treatments of infants at risk also decrease the incidence and severity of respiratory distress syndrome (2), and Kwong et al. (3) reported in abstract that maternal corticosteroid treatments improved the clinical response to subsequent surfactant treatments at birth. These clinical observations are consistent with the multiple reports of fetal lung maturation resulting from maternal corticosteroid treatments. A common theme of many of the studies was that the important effect of corticosteroids was to induce surfactant synthesis. Although maternal corticosteroid treatments increased alveolar pool sizes of unventilated preterm rabbits (4-6), no changes in alveolar surfactant were found after short-term ventilation $(4,7)$. Maternal corticosteroid treatments altered the lung function in ventilated 27-day gestational age rabbits independently of change in alveolar-saturated phosphatidylcholine pool sizes. Such treatments decreased protein leaks from the

Received July 27, 1988; accepted August 31, 1988.

Correspondence Michiko Ikegami, M.D., Department of Pediatrics, Building A17 Annex, Harbor-UCLA Medical Center, 1000 West Carson Street, Torrance, CA 90509.

Supported by Heaith and Human Development Grant HD-20618 from Child Health Development. vascular space to the lungs and increased protein leaks from the airspaces out of the lung, decreased lung rupture pressures, and dramatically improved the compliances and dose response curves of the rabbit lungs to surfactant $(4,7-10)$. Such altered responses were consistent with effects resulting from lung structural alterations mediated by corticosteroids (11). However, the preterm ventilated rabbits at 27 days of gestational age had severe lung immaturity, and over $10 \%$ of the total intravascular albumin leaked into the lungs after just $30 \mathrm{~min}$ of mechanical ventilation (9). This degree of pulmonary edema was more severe than that seen in infants with respiratory distress syndrome. Therefore, we asked if maternal corticosteroid treatments could alter protein leaks and surfactant responses at more advanced gestational ages.

\section{MATERIALS AND METHODS}

Corticosteroid treatments. Pregnant New Zealand White rabbits were given intramuscular injections with $0.1 \mathrm{mg} / \mathrm{kg}$ betamethasone (Celestone Soluspan, Schering-Plough Corp., Kenilworth, NJ) 48 and $24 \mathrm{~h}$ before preterm delivery at 27, 28, and 29 days of gestation or before term delivery at 31 days. The control does at each gestation receive injections with vehicle at the same times. Five to seven pregnant does were used for each control and corticosteroid-treated group at each gestational age.

Delivery and ventilation. The does were anesthetized with intravascular pentobarbital and were given oxygen by face mask. Lidocaine with epinephrine was used as supplemental anesthesia for the abdominal wall, and the fetuses were sequentially delivered, weighed and given $10 \mathrm{mg} / \mathrm{kg}$ ketamine and $0.1 \mathrm{mg} / \mathrm{kg}$ acepromazine by intraperitoneal injection. The trachea of each newborn was exposed through a small incision in the anterior neck, and a short tube made from a 17-gauge needle was tied into the trachea. Alternately delivered fetuses then received, via the endotracheal tube, either $3.8 \mathrm{ml} / \mathrm{kg}$ body weight saline containing $1 \mu \mathrm{Ci}^{125} \mathrm{I}$-albumin per animal or $3.8 \mathrm{ml} / \mathrm{kg}$ saline containing the ${ }^{125} \mathrm{I}$-albumin plus $50 \mathrm{mg} / \mathrm{kg}$ natural calf surfactant. Each rabbit was ventilated with $100 \%$ oxygen using an anesthesia bag and manometer for about five breaths and transferred to a ventilator-plethysmograph system that permitted the simultaneous ventilation of 10 newborn rabbits (7). The plethysmographs were a series of 10 clear plastic boxes, temperature-controlled at $37^{\circ} \mathrm{C}$, that were connected to 10 rebreathing circuits containing soda lime and driven by a Sechrist infant ventilator (Sechrist Industries, Anaheim, CA). The 27- and 28-day gestational age rabbits were ventilated at a rate of 40 breaths/min using an inspiratory time of $0.7 \mathrm{~s}$; the 29-day gestational age and newborn rabbits were ventilated at a rate of 30 breaths/min using a $0.7-\mathrm{s}$ inspiratory time. All animals were ventilated with $100 \%$ oxygen, and no positive end expiratory pressure was used to avoid the air trapping that seems to occur in preterm rabbits (7). Three litters of the 31-day gestation rabbits delivered spontaneously 1 to $3 \mathrm{~h}$ before being studied and the other litters were delivered by cesarean section and allowed to breathe for 1 to $2 \mathrm{~h}$ before 
being studied. These rabbits will be referred to as term newborn rabbits because there were no differences in the variables measured between rabbits delivered spontaneously and those delivered by cesarean section. The tidal volume of each rabbit was measured at least every $5 \mathrm{~min}$ with a pneumotachometer, and the peak inspiratory pressure was regulated independently for each rabbit to achieve a tidal volume of about 10 to $12 \mathrm{ml} / \mathrm{kg}(7)$. Compliance was calculated as a total lung compliance by dividing tidal volume by peak inspiratory pressure and the body weight in $\mathrm{kg}$.

Immediately after the start of mechanical ventilation, each rabbit received $75 \mu \mathrm{l} / 10 \mathrm{~g}$ body weight of saline containing $1 \mu \mathrm{Ci}$ ${ }^{131} \mathrm{I}$-albumin via the external jugular vein. The average time from delivery to albumin injection was $3 \mathrm{~min}$. After $30 \mathrm{~min}$ of ventilation, each rabbit was killed with an intrathecal injection of lidocaine and was disconnected from the ventilator. After the chest was opened to expose the heart, a heparinized heart blood sample was drawn. This blood sample was used to measure $\mathrm{PCO}_{2}$ $\mathrm{pH}$, labeled albumin, and $\mathrm{Hb}$ content. The sex of each rabbit was determined by examination of the internal gonads (5).

Processing of lungs. The chest was completely opened, and five aliquots of room temperature $0.9 \% \mathrm{NaCl}$ were used to fill the lungs visibly. Each aliquot was flushed into and out of the airways $3 \times(7,9)$. The recovered volumes, which were about $90 \%$ of the injected volumes, were saved as the pooled alveolar wash. The lung tissue was removed from the chest, weighed, and homogenized in $4 \mathrm{ml}$ of water. Aliquots of the homogenates and alveolar washes were used to measure labeled albumin and saturated phosphatidylcholine contents. Protein content of the alveolar washes was measured using the method of Lowry et al. (12). The hemoglobin measurements from the lung homogenate and blood together with measurements of labeled albumin in blood were used to correct for intravascular blood that remained in the lung tissue (13).

Materials and analytical techniques. Calf surfactant was isolated from alveolar washes from fresh, 1-day-old calf lungs by a series of centrifugation steps as previously described (14). Labeled albumins were prepared using chloramine $T$ and monomer standard BSA (Miles Laboratories, Inc., Elkhart, IN). The iodinated proteins were extensively dialyzed, and incorporation was verified by trichloroacetic acid precipitation (13). Hemoglobin was measured using Drabkin's solution. Lipid extracts of the lung homogenates and alveolar washes were treated with osmium tetroxide, and the saturated phosphatidylcholine was recovered by column chromatography using neutral alumina according to Mason et al. (15). Saturated phosphatidylcholine was quantified by measuring inorganic phosphorus according to Bartlett (16).

Data analysis. Animals were excluded from the final analysis if the terminal $\mathrm{pH}$ value was less than 7.0 or the $\mathrm{PCO}_{2}$ value was greater than $70 \mathrm{~mm} \mathrm{Hg}$. Values for all other surviving animals were reported. An analysis of variance followed by the Student Newman-Keul multiple comparison procedure was used to detect differences between the four groups at each gestational age and the similar groups across the four gestational ages. Compliance values were calculated for each rabbit at 10,20 , and 30 min. Significance was accepted at $p<0.01$ because we chose to concentrate on only the highly significant differences given the number of groups and comparisons.

\section{RESULTS}

Status of animals. The body weights of the corticosteroidtreated groups were less than for the control animals, and this weight difference was significant for many of the groups (Table 1). The mean $\mathrm{PCO}_{2}$ values were comparable for all animals, although the 27-day gestational age animals had a metabolic acidosis.

The mean compliance values for the control rabbits increased linearly with increasing gestational age (Fig. $1 A$ ). Surfactant treatment significantly improved compliances at 27,28 , and 29 days of gestation to compliance values not different from the term newborn rabbits. Therefore, the incremental increase in compliance resulting from the surfactant treatment fell significantly as gestational age increased (Fig. $1 B$ ). The corticosteroid treatment did not significantly improve compliance above control values at 27 days; however, there was a maximal and significant $58 \%$ increase in compliance at 29 days of gestational age. The combined use of corticosteroids and surfactant resulted in compliance values equivalent to the term newborn at all preterm gestational ages. These compliance values were significantly higher than either treatment alone at 27 days and 28 days of gestational age. These results showed maximal benefit of corticosteroids versus untreated animals at 29 days of gestation and of surfactant at 27 days of gestation, whereas the combined use of both agents was effective at both 27 and 28 days of gestational age. There were no differences for compliance responses based on sex of the rabbits for any of the groups.

Saturated phosphatidylcholine. The saturated phosphatidylcholine recovered by alveolar wash expressed as $\mu \mathrm{mol} / \mathrm{kg}$ body weight was not increased above control values by surfactant at any gestational age (Fig. 2). There was a gestational age-dependent increase in alveolar-saturated phosphatidylcholine. Total lung (alveolar wash plus lung homogenate)-saturated phosphatidylcholine was significantly higher in controls than corticosteroid-treated rabbits at 28 days of gestational age. There was less recovery of the treatment doses of surfactant in the alveolar washes at 27 days of gestational age in both the control and corticosteroid-treated groups. Fetal sex did not influence the saturated phosphatidylcholine pool sizes.

Protein leak measurements. The percentage of the intravascularly injected ${ }^{131}$ I-albumin recovered by alveolar wash decreased remarkably with increasing gestational age in control rabbits (Fig. 3). At term, only $0.25 \%$ of the albumin was recovered by alveolar wash, and none of the treatments altered this low recovery. Surfactant treatment decreased the protein recovery in the alveolar wash by over $85 \%$ at 27 and 28 days of gestational age; the percentage decreases were significant but less with the corticosteroid (Fig. 4). The maximal percentage change in leak from control values occurred with corticosteroids at 29 days of gestational age when the leak was decreased to a value not different from that measured for the term newborn animals. The combined use of corticosteroids and surfactant at 27 and 28 days of gestational age was not more effective than surfactant alone in terms of decreasing the protein leak from the vascular space to the lungs.

Less of the intratracheal ${ }^{125} \mathrm{I}$-labeled albumin was recovered in the alveolar wash of corticosteroid-treated groups than the other groups at 27 and 28 days of gestational age (Fig. 5). Overall, recovery increased as gestational age increased such that there were $85-90 \%$ mean recoveries in the term newborns with about $70 \%$ of the labeled albumin found in the alveolar washes.

The total protein recovered by alveolar wash decreased in the control 29-day gestational age and term newborn rabbits relative to the earlier gestational age control rabbits (Fig. 6). However, corticosteroid treatments did not result in less protein recovery at any gestational age. Surfactant treatments decreased protein recovery at the early gestational ages relative to control rabbits as did the combined treatment groups at 27 and 28 days of gestational age. Protein recoveries or protein leak measurements were not different based on the sex of the rabbits studied.

\section{DISCUSSION}

Corticosteroid treatments of the fetus either by direct fetal injections or by maternal injections changed numerous indicators of lung maturation in a variety of animal models (1). Most of the changes were related to effects on the surfactant system as assessed by precursor incorporation rates $(17,18)$, increased surfactant in fetal lung fluid or alveolar washes of fetal lungs (46 ) or changes in lung pressure-volume curves (19). High dose 
Table 1. Summary of animals*

\begin{tabular}{|c|c|c|c|c|c|c|c|c|c|}
\hline \multirow{2}{*}{$\begin{array}{l}\text { Gestational age } \\
\text { (day) }\end{array}$} & \multirow[b]{2}{*}{ Group } & \multicolumn{2}{|c|}{ Treatment } & \multirow[b]{2}{*}{ No. } & \multirow{2}{*}{$\begin{array}{c}\text { Body weight } \\
\text { (g) }\end{array}$} & \multirow{2}{*}{$\begin{array}{l}\text { Tidal vol } \\
\text { (ml/kg) }\end{array}$} & \multirow[b]{2}{*}{$\mathrm{pH}$} & \multirow{2}{*}{$\begin{array}{c}\mathrm{PCO}_{2} \\
(\mathrm{~mm} \mathrm{Hg})\end{array}$} & \multirow[b]{2}{*}{ Male/female } \\
\hline & & \pm Steroid & \pm Surfactant & & & & & & \\
\hline \multirow[t]{4}{*}{27} & 1 & - & - & 21 & $30.2 \pm 7.9$ & $11.3 \pm 1.8$ & $7.20 \pm 0.15$ & $36 \pm 12$ & $12 / 9$ \\
\hline & 2 & + & - & 18 & $26.8 \pm 4.3$ & $12.6 \pm 1.6$ & $7.28 \pm 0.09$ & $32 \pm 6$ & $11 / 7$ \\
\hline & 3 & - & + & 15 & $30.1 \pm 4.8$ & $12.0 \pm 1.2$ & $7.18 \pm 0.14$ & $35 \pm 11$ & $5 / 10$ \\
\hline & 4 & + & + & 19 & $25.8 \pm 4.1$ & $12.9 \pm 1.6$ & $7.23 \pm 0.18$ & $28 \pm 6$ & $13 / 6$ \\
\hline \multirow[t]{4}{*}{28} & 5 & - & - & 14 & $33.0 \pm 5.1$ & $11.7 \pm 2.1$ & $7.21 \pm 0.07$ & $29 \pm 6$ & $7 / 7$ \\
\hline & 6 & + & - & 16 & $26.9 \pm 4.3$ & $12.8 \pm 2.0$ & $7.33 \pm 0.12$ & $31 \pm 2$ & $7 / 9$ \\
\hline & 7 & - & + & 11 & $33.6 \pm 5.8$ & $12.5 \pm 1.5$ & $7.30 \pm 0.09$ & $26 \pm 4$ & $9 / 2$ \\
\hline & 8 & + & + & 13 & $26.6 \pm 4.1$ & $12.9 \pm 0.9$ & $7.38 \pm 0.10$ & $28 \pm 1$ & $5 / 8$ \\
\hline \multirow[t]{4}{*}{29} & 9 & - & - & 19 & $39.5 \pm 8.1$ & $10.6 \pm 1.7$ & $7.30 \pm 0.11$ & $35 \pm 10$ & $12 / 7$ \\
\hline & 10 & + & - & 20 & $32.7 \pm 4.9$ & $11.4 \pm 1.3$ & $7.30 \pm 0.10$ & $33 \pm 5$ & $9 / 11$ \\
\hline & 11 & - & + & 16 & $39.5 \pm 9.8$ & $11.3 \pm 1.3$ & $7.29 \pm 0.10$ & $33 \pm 7$ & $8 / 8$ \\
\hline & 12 & + & + & 19 & $33.5 \pm 4.4$ & $11.4 \pm 1.0$ & $7.27 \pm 0.12$ & $30 \pm 5$ & $10 / 9$ \\
\hline \multirow[t]{4}{*}{ Term } & 13 & - & - & 17 & $57.0 \pm 6.0$ & $10.1 \pm 1.0$ & $7.32 \pm 0.10$ & $38 \pm 8$ & $6 / 11$ \\
\hline & 14 & + & - & 15 & $39.9 \pm 12.4$ & $10.5 \pm 1.2$ & $7.27 \pm 0.13$ & $37 \pm 8$ & $5 / 10$ \\
\hline & 15 & - & + & 14 & $57.6 \pm 7.1$ & $10.5 \pm 0.3$ & $7.34 \pm 0.08$ & $37 \pm 7$ & $8 / 6$ \\
\hline & 16 & + & + & 13 & $46.4 \pm 7.8$ & $10.5 \pm 0.5$ & $7.31 \pm 0.04$ & $38 \pm 2$ & $8 / 5$ \\
\hline
\end{tabular}

* All values given as mean $\pm \mathrm{SD}$. The significant differences within the gestational age groups at $p<0.01$ were body weights for group $5>6,8$ at 28 days of gestational age, group $9>10$ at 29 days of gestational age and groups 13,15>14, 16 at term. The only other difference was that group 5 had a lower $\mathrm{pH}$ than did group 8 at 28 days of gestational age.

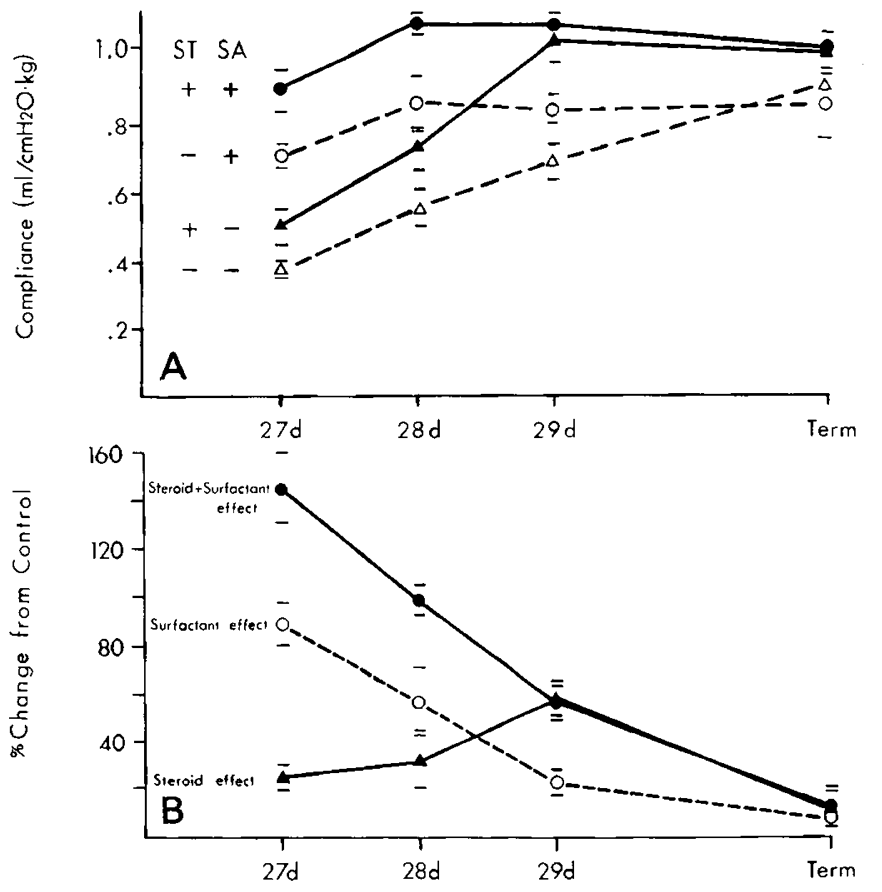

Fig. 1. Compliance values for the ventilated rabbits. $A$, the four groups of rabbits are indicated by the signs below corticosteroid $(S T)$ and surfactant $(S A)$ treatments. Values are means \pm SE for the groups calculated from the mean compliance value measured at 10,20 , and 30 min of age for each rabbit. Term newborn rabbits are indicated as Term. $B$, the changes in compliance are calculated by subtracting the values for each animal from the groups from the mean values for the control groups. The curves are labeled to indicate the effect being measured versus the control groups. Compliance increased significantly in the control groups. Surfactant increased compliance versus control at 27 and 28 days of gestational age, and the combined treatments increased compliance at 27,28 , and 29 days of gestational age ( $p<0.01$ for all comparisons).

corticosteroids given directly to the fetus induced type II cell morphologic maturation in the fetal rabbit $(6,20)$, and high dose maternal corticosteroid treatments increased alveolarization in the fetal monkey (21). Kauffman (22) found that the volume

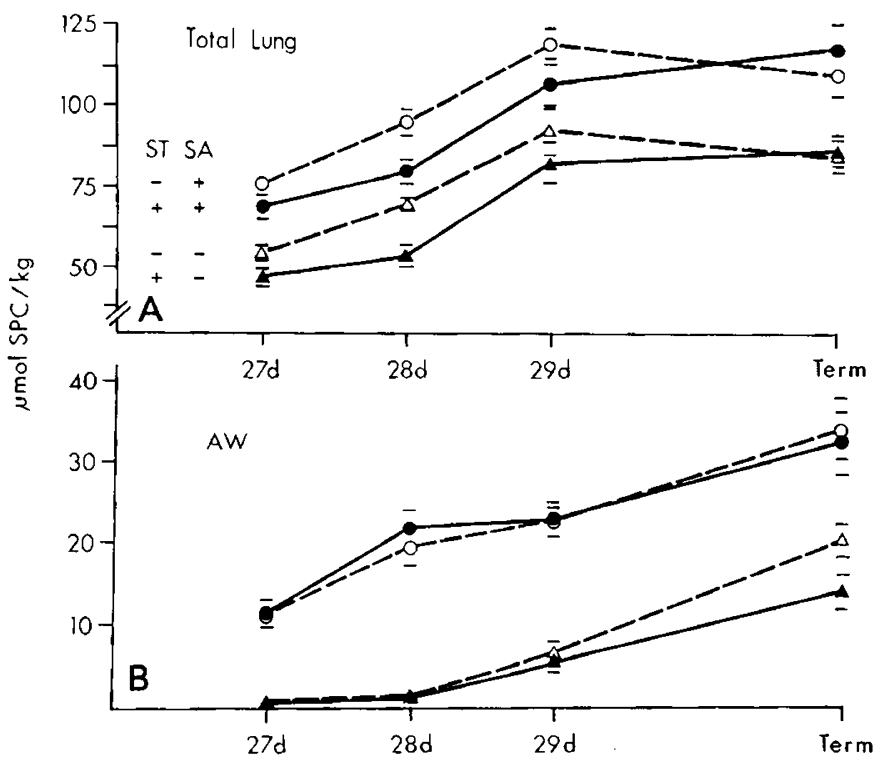

Fig. 2. Saturated phosphatidylcholine $(S P C)$ pool sizes given as means \pm SE. $A$, the four groups of rabbits are indicated by the signs below corticosteroid $(S T)$ and surfactant $(S A)$ treatments. Total lung saturated phosphatidylcholine (alveolar wash plus lung homogenate) increased in the corticosteroid and control groups to 29 days of gestation. The control value was higher than the corticosteroid group at 28 days of gestational age. Surfactant increased the pool sizes. $B$, alveolar wash $(A W)$ saturated phosphatidylcholine increased with gestational age but was not changed by corticosteroids. Surfactant treatment increased the pool sizes recovered by alveolar wash by $12 \mu \mathrm{mol} / \mathrm{kg}$ at 27 days of gestational age and by about $20 \mu \mathrm{mol} / \mathrm{kg}$ at the other gestational ages.

density of airspaces increased more rapidly and at lower doses of maternal corticosteroids in fetal mouse lungs than did morphologic maturation of type II cells.

The total corticosteroid dose of $0.2 \mathrm{mg} / \mathrm{kg}$ betamethasone that we used was lower than used by most investigators in rabbits $(4$, $5,17)$. However, this dose did cause the expected fetal growth retardation, and Devaskar et al. (23) recently documented alterations of pressure-volume curves in rabbits using half the dose used in this study. We found that the corticosteroid dose used 


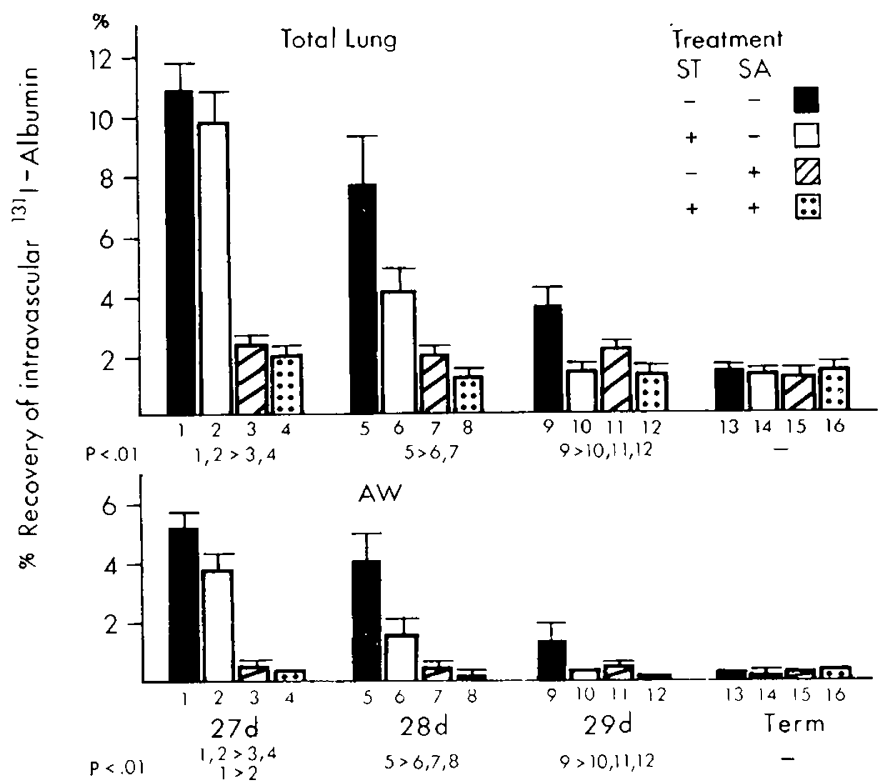

Fig. 3. Percentage of recovery of intravascular ${ }^{131} \mathrm{I}$-albumin from the total lung (alveolar wash plus lung homogenate) and alveolar wash $(A W)$. The treatment groups and means $\pm S E$ values are indicated on the figure. Corticosteroids $(S T)$, surfactant $(S A)$, and the combined treatments decreased the percentage of recoveries relative to control values at all gestations except the term newborns. The surfactant effect was larger than the corticosteroid effect at 27 and 28 days of gestational age for the total lung and alveolar wash.

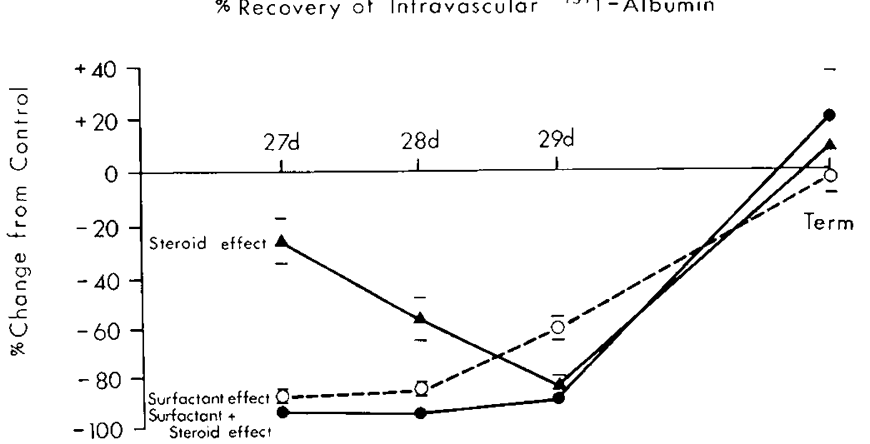

Fig. 4. Percentage of change in ${ }^{131} \mathrm{I}$-albumin leak values for treated relative to untreated groups at each gestational age. The mean $\pm \mathrm{SE}$ differences at each gestation between the treatment groups and the mean values for the untreated groups were calculated. Corticosteroids decreased the magnitude of the leak relative to controls to 29 days of gestation. Large effects were seen with surfactant and surfactant plus corticosteroids in the preterm animals, and no effects were found in the term newborns.

here did not increase the compliance of ventilated 27-day gestational age rabbit lungs (7). However, the maternal corticosteroid treatments improved the response of the lungs to surfactant, decreased vascular to alveolar protein leaks, decreased lung rupture pressures, and changed the dose-response curve for exogenous surfactant $(7-10)$. Whereas the corticosteroid dose used for these studies was comparable on a per $\mathrm{kg}$ body weight basis to that used clinically to induce lung maturation, there are large differences in fetal rodent and human growth rates and relative durations of exposure to the corticosteroids during late gestation. The effects that we noted occurred in the absence of a change in alveolar-saturated phosphatidylcholine pool size measured after ventilation of the rabbits, and implied primarily structural effects of corticosteroids on the fetal lungs. Fiascone et al. (4) recently reported that twice the dose of betamethasone used here increased alveolar wash saturated phosphatidylcholine from the

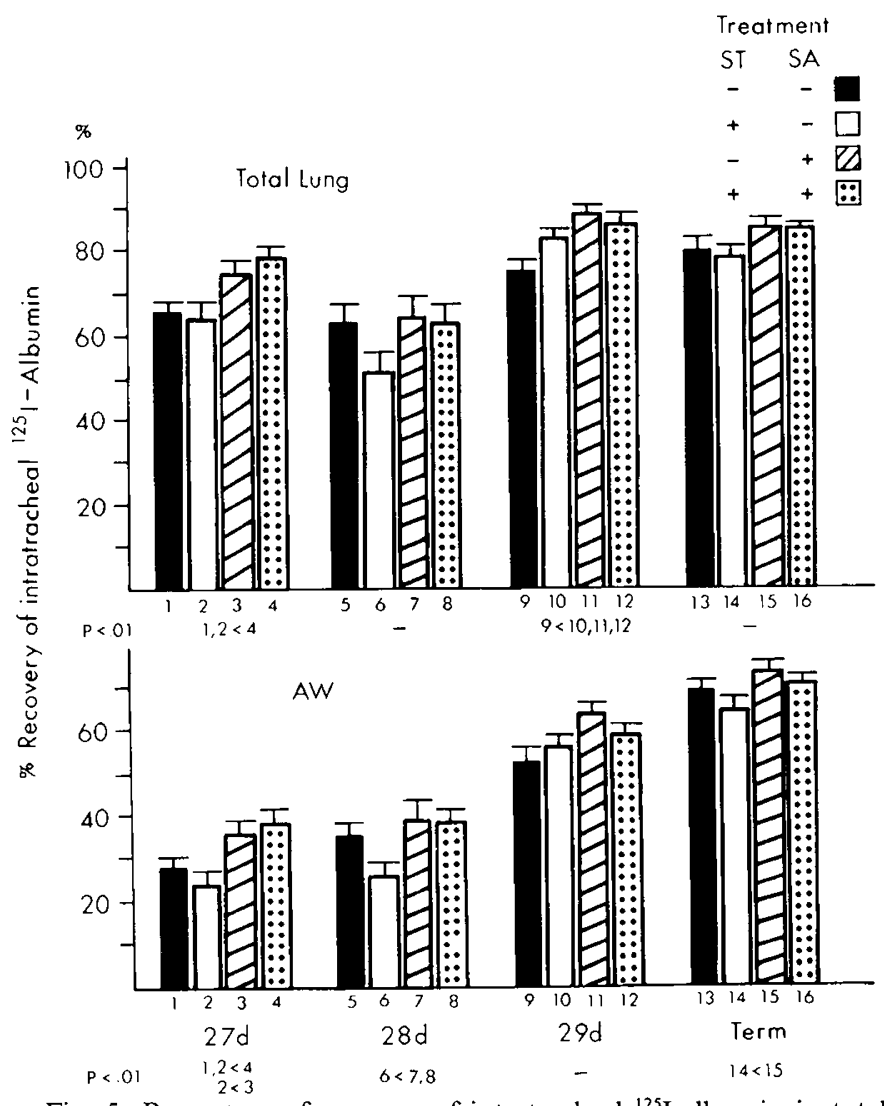

Fig. 5. Percentage of recovery of intratracheal ${ }^{125} \mathrm{I}$-albumin in total lung and alveolar wash $(A W)$. The treatment groups and mean $\pm \mathrm{SE}$ values are indicated on the figure. Percentage of recoveries increased in the total lungs and alveolar washes at 29 days of gestation and in term newborns relative to the earlier gestations. Corticosteroids decreased the alveolar wash recovery at 28 days relative to the other groups. Surfactant treatments increased recoveries in alveolar washes and total lungs relative to the groups not treated with surfactant at 27 days of gestational age.

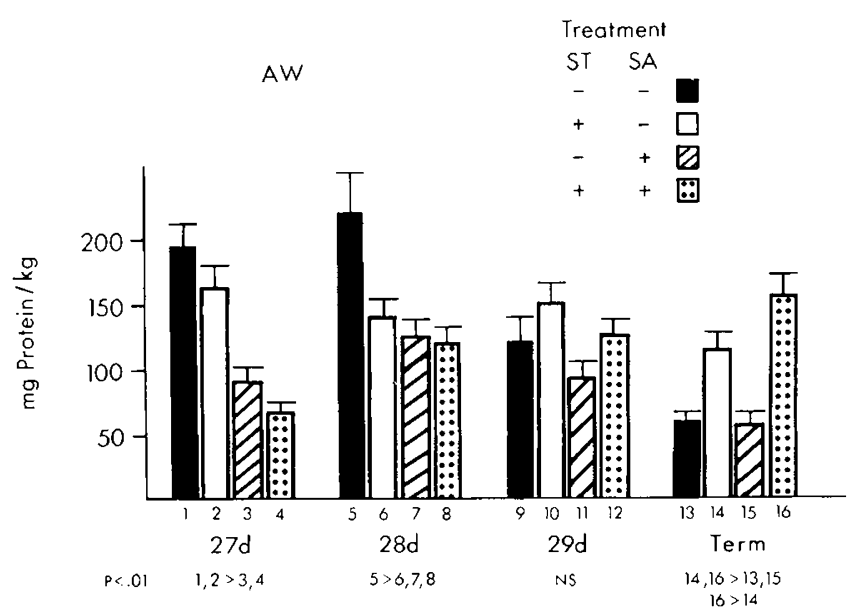

Fig. 6. Amount of protein in alveolar washes $(A W)$. Surfactant $(S A)$ treated groups had lower protein recoveries at 27 and 28 days of gestational age relative to control values. All treatment groups were less than control at 28 days of gestational age. The corticosteroid (ST)-treated groups were higher than the other groups in the term newborn rabbits. All values are given as means $\pm \mathrm{SE}$.

lungs of unventilated fetuses, but no effect could be detected after a period of ventilation. We found no increase of alveolar saturated phosphatidylcholine pool sizes in ventilated animals at any of the gestational ages studied after maternal corticosteroid treatment. The pool sizes were very small at 27 and 28 days of 
gestational age and were below the minimal dose of $>5 \mathrm{mg} / \mathrm{kg}$ of exogenous surfactant needed to improve compliances in $27-$ day gestational age control animals (10). However, the improved compliance of the 29 days of gestational age corticosteroidtreated rabbits relative to controls could result from a better response of the lungs to the low amounts of surfactant present.

Corticosteroid treatments of the postnatal rat decreased the rate of airway clearance of small molecular weight solutes (24), indicating effects on the postnatal alveolar epithelium at a time when alveolarization was occurring. Such treatments also changed the pattern and timing of postnatal alveolarization (25). Because pulmonary edema and subsequent interference by the alveolar edema with surfactant function is characteristic of respiratory distress syndrome (26), we thought that treatment of the fetal lung with corticosteroids might alter the alveolar and airway epithelium such that the large protein leak characteristic of the preterm lung might be decreased. Because the term newborn and adult lung was quite impermeable to protein, the change from a leaky lung to a protein-impermeable lung could be a maturational phenomenon (27). Ventilated preterm surfactant deficient lungs might leak protein because of structural immaturity rather than just from barotrauma resulting in focal overdistention and epithelial rupture (13). At 27 days of gestational age, the magnitude of the leak was very large, and the corticosteroid treatment decreased the leak only modestly. The corticosteroids had larger relative effects at 28 and 29 days of gestational age when the protein leak was less in control animals. Because corticosteroids did not significantly improve compliance or alter alveolar surfactant pool sizes at 28 days of gestational age, the effects on protein leak from the vascular space to the alveoli should have been independent of barotrauma or surfactant. The decreased leak at 29 days of gestation might be explained by the improved compliance and therefore decreased barotrauma; however, the mean peak inspiratory pressures were all relatively low at 29 days of gestational age. These low pressures should not have caused much barotrauma. This study demonstrated that corticosteroids decreased protein leaks from the vascular to the alveolar compartments at all preterm gestations tested, although the mechanisms of the effects could differ at the different gestational ages.

Surfactant treatments decreased the protein leaks to similar low values at all three preterm gestations, and the magnitude of the effect indicated that the major cause of the protein accumulation into lung tissue and airspaces was surfactant deficiency. There was a 2.7 -fold decrease in airspace leak and a $62 \%$ decrease in total lung leak with surfactant treatment at 29 days of gestational age even though compliance did not improve. Possibly the large amount of surfactant made inflation more uniform and thus minimized focal overdistention without decreasing compliance, but large amounts of surfactant also could have primary effects on the airspace epithelium that could alter protein leak.

The leak of protein from the airspaces tended to be increased at early gestational ages as reported previously (7). This effect was thought to have resulted from a possible increase in airspace surface area after corticosteroid treatments. Another possibility was the maturation of the fluid clearance behavior of the fetal lung characterized by a transient pore size increase in the immediate newborn period (27). However, no such effects were noted after corticosteroid treatments at 29 days of gestation and in term newborn rabbits. The recovery of protein by alveolar wash was not consistent with the measurements of labeled albumin movement in that the corticosteroid-treated 29-day and term newborn rabbits had high protein recoveries despite very low leak measurements. The increased protein recoveries represented protein present in the fetal lung fluid before delivery rather than a protein leak after delivery.

Our recent studies of the effects of maternal corticosteroids and thyroid-releasing hormone on subsequent lung function deemphasized the importance of surfactant-mediated effects of these agents and indicated that integrated structural changes resulted from such hormone exposures (9). This conclusion was consistent with the anatomic observations of changes in maturation $(6,20,28)$. Striking and additive effects of hormone treatments on type II cells occurred in vitro, and such in vitro systems were used primarily for studies of mechanisms of hormone action $(28-30)$. Smith and his colleagues $(30,31)$ proposed that the primary effect of corticosteroids was mediated by a mesenchymal-epithelial interaction resulting from corticosteroid induction of fibroblasts to produce a fibroblast-pneumocyte factor that then signaled the type II cells to produce surfactant. Mesenchymal-epithelial interactions are central to early lung development. Our results were consistent with a generalization of the fibroblast-pneumocyte factor model such that the fibroblast-derived signals could be more global signals that direct different cells and metabolic pathways toward maturation. Whatever the mechanisms, these studies documented potentially clinically important effects of corticosteroids on lung function across gestational ages in late gestation rabbits. The additive effects of corticosteroids and surfactant were particularly remarkable at the earlier gestational age.

\section{REFERENCES}

1. Ballard PL 1986 Hormones and Lung Maturation. Springer-Verlag, Berlin

2. Jobe A, Ikegami M 1987 Surfactant for the treatment of respiratory distress syndrome. Am Rev Respir Dis 136:1256-1275

3. Kwong M, Egan E, Notter R 1987 Synergistic response of antenatal betamethasone and tracheal instillation of calf lung surfactant extract at birth Pediatr Res 21:458A

4. Fiascone JM, Jacobs HC, Moya FR, Mercurio MR, Lima DM 1987 Betamethasone increases pulmonary compliance in part by surfactant independent mechanisms in preterm rabbits. Pediatr Res 22:730-735

5. Freese WB, Hallman M 1983 The effect of betamethasone and fetal sex on synthesis and maturation of lung surfactant phospholipids in rabbits. Biochim Biophys Acta 750:47-59

6. Motoyama K, Orzalesi MM, Kikkawa Y, Kaibara M, Wu B, Zigas CJ, Cook CD 1971 Effect of cortisol on the maturation of fetal rabbit lungs. Pediatrics 48:547-555

7. Ikegami M, Berry D, El Kady T, Pettenazzo A, Seidner S, Jobe A 1987 Corticosteroids and surfactant change lung function and protein leaks in the lungs of ventilated premature rabbits. J Clin Invest 79:1371-1378

8. El Kady T, Jobe A 1987 Corticosteroids and surfactant increase lung volumes and decrease rupture pressures of preterm rabbit lungs. J Appl Physiol 63:1616-1621

9. Ikegami M, Jobe AH, Pettenazzo A, Seidner SR, Berry DD, Ruffini L 1987 Effect of maternal treatment with corticosteroids, $T_{3}$, TRH and their combinations on lung function of ventilated preterm rabbits with and without surfactant treatments. Am Rev Respir Dis 136:892-898

10. Seidner S, Pettenazzo A, Ikegami M, Jobe A 1988 Corticosteroid potentiation of surfactant dose response in preterm rabbits. J Appl Physiol 64:2366-2371

11. Schellenberg J-C, Liggins GC, Kitterman JA, Lee C-CH 1987 Elastin and collagen in the fetal sheep lung: II: relationship to mechanical properties of the lung. Pediatr Res 22:339-343

12. Lowry OH, Rosebrough NJ, Farr AL, Randall RJ 1951 Protein measurement with the Folin phenol reagent. J Biol Chem 193:265-275

13. Jobe A, Jacobs H, Ikegami M, Berry D 1985 Lung protein leaks in ventilated lambs: effect of gestational age. J Appl Physiol 58:1246-1251

14. Jobe A, Ikegami M 1984 The prematurely delivered lamb as a model for studies of neonatal adaptation. In: Nathanielsz, PW (ed) Animal Models in Fetal Medicine. Perinatology Press, New York, pp 1-30

15. Mason RJ, Nellenbogen J, Clements JA 1976 Isolation of disaturated phosphatidylcholine with osmium tetroxide. J Lipid Res 17:281-284

16. Bartlett GR 1959 Phosphorus assay in column chromatography. J Biol Chem 234:466-468

17. Possmayer F, Casola P, Chan F, Hill S, Metcalf IL, Stewart-DeHaan PJ, Wong T, Heras JL, Gammal EB, Harding PGR 1979 Glucocorticoid induction of pulmonary maturation in rabbit fetus: the effect of maternal injection of betamethasone on the activity of enzymes in fetal lung. Biochim Biophys Acta 574:197-211

18. Rooney SA, Gobran LI, Marino PA, Maniscalco WM, Gross I 1982 Effects of betamethasone on phospholipid content, composition and biosynthesis in fetal rabbit lung. Biochim Biophys Acta 572:64-76

19. Kotas RV, Avery ME 1971 Accelerated appearance of pulmonary surfactant in the fetal rabbit. J Appl Physiol 30:358-361

20. Wang NS, Kotas RV, Avery ME, Thurlbeck WM 1971 Accelerated appearance of osmiophilic bodies in fetal lungs following steroid injection. J Appl Physiol 30:362-365

21. Bunton TE, Plopper CG 1984 Triamcinolone-induced structural alterations in the development of the lung of the fetal rhesus macaque. Am $\mathbf{J}$ Obstet Gynecol 148:203-215

22. Kauffman SL 1977 Acceleration of canalicular development in lungs of fetal mice exposed transplacentally to dexamethasone. Lab Invest 36:395-40 I

23. Devaskar U, Church JC, Chechani V, Sadiq F 1987 Effect of simultaneous 
administration of betamethasone and triiodothyronine (T3) on development of functional pulmonary maturation in fetal rabbits. Biochem Biophys Res Commun 146:524-529

24. Hemberger JA, Schanker LS 1981 Effect of cortisone on permeability of the neonatal rat lung to drugs. Biol Neonate 40:99-104

25. Massaro D, Teich N, Maxwell S, Massaro GC, Whitney P 1985 Regulation and evidence for a critical period in rats. $\mathrm{J}$ Clin Invest 76:1297-1305

26. Ikegami M, Jobe A, Berry D 1986 A protein that inhibits surfactant in respiratory distress syndrome. Biol Neonate 50:121-129

27. Egan EA, Olver RE, Strang LB 1975 Changes in non-electrolyte permeability of alveoli and the absorption of lung liquid at the start of breathing in the lamb. J Physiol 244:161-179

28. Gonzales LW, Ballard PL, Ertsey R, Williams MC 1986 Glucocorticoids and thyroid hormones stimulate biochemical and morphological differentiation of human fetal lung in organ culture. J Clin Endocrinol Metab 62:678-691

29. Gross I, Wilson CM 1982 Fetal lung in organ culture IV: supraadditive hormone interactions. J Appl Physiol 52:1420-1425

30. Smith BT, Sabry K 1983 Glucocorticoid-thyroid synergism in lung maturation a mechanism involving epithelial-mesenchymal interaction. Proc Natl Acad Sci USA 80:1951-1954

31. Post M, Barsoumian A, Smith BT 1986 The cellular mechanism of glucocorticoid acceleration of fetal lung maturation. J Biol Chem 261:2179-2184

The Society for Behavioral Pediatrics will conduct its 7th Annual Meeting in Cambridge, MA on November 9-10, 1989. A special session honoring Dr. T. Berry Brazelton will be held on November 11, 1989. We invite you to submit abstracts of research papers for consideration for presentation at the scientific sessions. ABSTRACTS MUST BE RECEIVED BY APRIL 30, 1989. For further information and abstract forms, please contact: Ms. Noreen Spota, SBP Business Administrator, 241 East Gravers Lane, Philadelphia, PA 19118 (215) 248-9168.

\section{Announcements}

\section{Annual Meetings}

The American Pediatric Society, the Society for Pediatric Research, and the Ambulatory Pediatric Association will have meetings on May 1-5, 1989 at the Washington Sheraton Hotel, Washington, D.C.

Contact: SPR-Ms. Debbie Wogenrich, 2650 Yale Blvd., S.E., Suite 104, Albuquerque, NM 87106 (505) 7649099. APS-Dr. Audrey K. Brown, Secretary-Treasurer, Department of Pediatrics, SUNY, Health Science Center at Brooklyn, 450 Clarkson Avenue, Box 49, Brooklyn, NY 11203, (718) 270-1692. APA-Ambulatory Pediatric Association, 6728 Old McLean Village, McLean, VA 22101 (703) 556-9222.

\section{European Chief Editor}

Since the term of European Chief Editor Dr. Kari O. Raivio will expire at the end of 1989, the position of European Chief Editor of Pediatric Research will be open.

Duties include evaluation and editorial decisions regarding European manuscripts and collaboration with the Editor-in-Chief and the Board of Trustees of the International Pediatric Research Foundation toward developing the journal scientifically. Financial support for the office is provided.

Interested applicants should submit a curriculum vitae and the names of at least four local editors from different fields of pediatrics who would help evaluate manuscripts. Inquiries and applications should be sent by March 1, 1989 to: Dr. Kari O. Raivio, University of Helsinki, Children's Hospital, 00290 Helsinki, Finland. 